\title{
Experimental determination of UV- and VIS- lidar overlap function
}

\section{Determinación experimental de las funciones de solapamiento lidar visible y ultravioleta}

\author{
N. Rogelj(1,*), J. L. Guerrero-Rascado(2,3),F. Navas-Guzmán(2,3,4),J. A. Bravo-Aranda(2,3), \\ M. J. Granados-Muñoz ${ }^{(2,3)}$, L. Alados-Arboledas(2,3)
}

1. Color Informatics and Media Technology (CIMET), coordinated by University Jean Monnet, Faculty of Science and Technology, Saint-Etienne, France.

2. Andalusian Institute for Earth System Research (IISTA-CEAMA), University of Granada, Junta de Andalucía, Av. del Mediterráneo s/n, 18006 Granada, Spain.

3. Department of Applied Physics, University of Granada, Av. Fuentenueva s/n, 18071 Granada, Spain. 4. Institute of Applied Physics (IAP), University of Bern, Bern, Switzerland.

(*) Email: n.above@gmail.com

Received / Recibido: 15/02/2014. Revised / Revisado: 02/06/2014. Accepted / Aceptado: 10/06/2014.

DOI: http://dx.doi.org/10.7149/OPA.47.3.169

\begin{abstract}
:
This study focuses on the retrieval of lidar overlap functions at two wavelenghts (355 and $532 \mathrm{~nm}$ ) for the lidar routinely operated at the EARLINET Granada station, placed in the southeastern Iberian Peninsula. For this aim, aerosol backscatter coefficients retrieved from both Raman and elastic lidar signals were used. The method is based on the fact that aerosol backscatter profiles derived from elastic signals suffer from incomplete overlap effect whereas those retrieved from Raman signals are unaffected. This article reports about the reproducibility of the lidar overlap functions under different atmospheric scenarios and also the impact of some features of the iterative process itself.
\end{abstract}

Key words: Overlap Function, Iterative Technique, Raman Lidar.

\section{RESUMEN:}

Este estudio se centra en la obtención de las funciones de solapamiento lidar en dos longitudes de onda (355 y $532 \mathrm{~nm}$ ) del lidar operado rutinariamente en la estación Granada de EARLINET, situada en el sureste de la Península Ibérica. Para tal fin se usaron los coeficientes de retrodispersión de aerosol obtenidos a partir de señales Raman y elásticas. El método se basa en el hecho de que los perfiles de retrodispersión de aerosol derivados a partir de señales elásticas sufren de solapamiento incompleto mientras que aquellos obtenidos mediante señales Raman no están afectados. Este artículo trata sobre la reproducibilidad de las funciones de solapamiento lidar bajo diferentes escenarios atmosféricos y también sobre el impacto de algunas características del propio proceso iterativo.

Palabras clave: Función de Solapamiento, Técnica Iterativa, Lidar Raman.

\section{REFERENCES AND LINKS / REFERENCIAS Y ENLACES}

[1]. J. L. Guerrero-Rascado, M. J. Costa, D. Bortoli, A. M. Silva, H. Lyamani, L. Alados-Arboledas, "Infrared lidar overlap function: an experimental determination", Opt. Express 18, 20350-20359 (2010). DOI

[2]. W. Gong, F. Mao, J. Li, "OFLID: Simple method of overlap factor calculation with laser intensity distribution for biaxial lidar", Opt. Commun. 284, 2966-2971 (2011). DOI

[3]. J. V. Hey, J. Coupland, M. H. Foo, J. Richards, A. Sandford, "Determination of overlap in lidar systems", Appl. Opt. 50, 5791-5797 (2011). DOI

[4]. F. Mao,W. Gong, J. Li, "Geometrical form factor calculation using Monte Carlo integration for lidar", Opt. Laser Technol. 44, 907-912 (2012). DOI 
[5]. A. C. Povey, R. G. Grainger, D. M. Peters, J. L. Agnew, D. Rees, "Estimation of a lidar's overlap function and its calibration by nonlinear regression", Appl. Opt. 51, 5130-5143 (2012). DOI

[6]. U. Wandinger, A. Ansmann, "Experimental determination of the lidar overlap profile with Raman lidar", Appl. Opt. 41, 511-514 (2002). DOI

[7]. http://www.atmosfera.ugr.es

[8]. F. Navas-Guzmán, J. L. Guerrero-Rascado, L. Alados-Arboledas, "Retrieval of the lidar overlap function using Raman signals", Opt. Pura Apl. 44, 71-75 (2011).

[9]. J. L. Guerrero-Rascado, B. Ruiz Reverter, L. Alados-Arboledas, "Multi-spectral Lidar characterization of the vertical structure of Saharan dust aerosol over Southern Spain", Atmos. Environ. 42, 2668-2681 (2008). DOI

[10]. J. L. Guerrero-Rascado, F. J. Olmo Reyes, I. Avilés-Rodríguez, F. Navas-Guzmán, D. Pérez-Ramírez, H. Lyamani, L. Alados-Arboledas, "Extreme Saharan dust event over the Southern Iberian Peninsula in September 2007: Active and passive remote sensing from surface and satellite", Atmos. Chem. Phys. 9, 8453-8469 (2009). DOI

[11]. J. D. Klett, "Stable analytic inversion solution for processing lidar returns", Appl. Opt. 20, 211-220 (1981). DOI

[12]. J. D. Klett, "Lidar inversion with variable backscatter/extinction ratios", Appl. Opt. 24, 1638-1643 (1985). DOI

[13]. F. G. Fernald, B. M. Herman J. A. Reagan, "Determination of aerosol height distribution by lidar", J. Appl. Meteorol. 11, 482-489 (1972). DOI

[14]. F. G. Fernald, "Analysis of atmospheric lidar observations: Some comments", Appl. Opt. 23, 652-653 (1984). DOI

[15]. A. Ansmann, U. Wandinger, M. Riebesell, C. Weitkamp, W. Michaelis, "Independent measurement of extinction and backscatter profiles in cirrus clouds by using a combined Raman elastic-backscatter lidar", Appl. Opt. 31, ,7113-7131 (1992). DOI

\section{Introduction}

The incomplete overlap between the laser beam and the receiver field of view significantly affects lidar observations in the near range. Because of this, the study of the lowermost layers of the troposphere and the determination of the planetary boundary layer height could be not possible. Therefore, the determination of the socalled lidar overlap function (range-dependent) is necessary.

The methods to derive the lidar overlap function are typically divided into two major groups, namely theoretical and experimental methods. A report of the main studies regarding determination of the lidar overlap function is given in [1] and references herein. In addition, the recently published studies related to both theoretical and experimental approaches demonstrate that still more research is needed [2-5]. In this study, the overlap functions for the Raman lidar MULHACEN (model LR331D400, Raymetrics, S.A.) operated at the EARLINET Granada station [6] are characterized at 355 and $532 \mathrm{~nm}$ using a simple technique proposed by
[7], in order to perform a further step on the results obtained previously by [8]. MULHACEN is a biaxial lidar system pointing to the zenith with a $40 \mathrm{~cm}$-diameter telescope. A full description can be seen at $[9,10]$.

\section{Methodology}

\subsection{Lidar equation}

Detected lidar signal can be written as (omitting wavelength dependence for simplicity):

$$
P(z)=K \frac{O(z)}{z^{2}} \beta(z) T^{2}(z),
$$

where $P$ is the power received from a distance $z$, $K$ is a height-independent system factor, that depends on average pulse energy, area of the receiver optics and overall system efficiency. This factor is completely determined by the lidar setup. $O(z)$ is the overlap function, which describes the incomplete overlap between the laser beam and the receiver field of view, and is the main subject of this paper. The atmospheric information is contained in the last two factors. The term $\beta(z)$ is the backscatter coefficient at 
distance $z$. It stands for the ability of the atmosphere to scatter light back into the direction from which it comes. $T^{2}(z)$ is the transmission term and describes how much light gets lost on the way from the lidar to distance $z$ and back.

\subsection{Retrieval of the lidar overlap function}

The method is based on the simultaneous measurement of a pure molecular Raman backscattered signal in addition to the elastic backscattered signal performed with an aerosol Raman lidar [8]. This method works without the need to know the instrumental parameters of the lidar system. The main assumption is that the difference between the overlap functions for both the elastic backscatter and the Raman signals can be neglected as the optical path for the Raman and elastic signals differ only in the wavelength separation unit, and the drawback is that an a priori value of aerosol lidar ratio (extinction-to-backscatter ratio) must be fixed as input for the Klett-Fernald method [11-14] (typically a height-independent value). Because the Raman signal is weaker than the background signal caused by the sunlight, the measurements used for computing overlap function can only be obtained during night-time. In order to improve the signal-to-noise ratio, 30-min average profiles were used to retrieve the overlap function.

The lidar equations for the elastic and the Raman signals can be written as:

$$
\begin{aligned}
P_{0}(z)=K_{0} \frac{O_{0}(z)}{z^{2}} \times \\
\quad \times\left\{\beta_{0, a e r}(z)+\beta_{0, m o l}(z)\right\} T_{0}^{2}(z), \\
P_{R a}(z)=K_{R a} \frac{O_{R a}(z)}{z^{2}} \beta_{R a}(z) T_{0}(z) T_{R a}(z),
\end{aligned}
$$

where subscript 0 and $R a$ refers to laser emitted and Raman shifted wavelengths, respectively.

The method used here is an iterative approach based on the fact that the deviation between the Klett-Fernald solution for the backscatter coefficient, $\beta_{\text {Klett }}(z)$ (which is calculated from the elastic signals [15]) and $\beta_{\text {Raman }}(z)$ (which is computed from the Raman shifted backscattered signal), is due to the incomplete overlap effect. Here, the lidar ratio profile (or alternatively an effective value representative for the whole atmospheric column) is needed as an input for the KlettFernald procedure [11-14]. This iterative approach is based on the fact that the elastic backscattered signal, after corrections for range and overlap dependency, is proportional to the total backscatter coefficient:

$$
P_{0}(z) O(z)^{-1} z^{2} \propto \beta_{\text {Raman }}(z)+\beta_{0, \text { mol }}(z) .
$$

In this way the Raman retrieval procedure provides backscatter coefficients in the near range, due to the use of the ratio of backscattered signals with similar overlap effects. In contrast, the elastic signal, only corrected for the range dependence, is mainly a function of the combined effect of total backscatter and the range-dependent overlap. This dependency is expressed by means of the Klett solution,

$$
P_{0}(z) z^{2} \propto \beta_{\text {Raman }}(z)+\beta_{0, \text { mol }}(z) .
$$

The relative difference between the Klett and the Raman lidar solutions,

$$
\begin{aligned}
& \frac{\beta_{\text {Raman }}(z)-\beta_{\text {Klett }}(z)}{\beta_{\text {Raman }}(z)+\beta_{\text {Klett }}(z)} \propto \\
& \quad \propto \frac{P_{0}(z) O(z)^{-1} z^{2}-P_{0}(z) z^{2}}{P_{0}(z) O(z)^{-1} z^{2}} \propto 1-O(z) .
\end{aligned}
$$

is used iteratively to reduce the overlap effect on the aerosol signal. In the first step $(i=1)$, the Klett-Fernald method is applied for the uncorrected elastic backscatter signal $\beta_{\text {Klet } ; i=1}(z)$ is used to solve the expression:

$$
\Delta O_{i}(z)=\frac{\beta_{\text {Raman }}(z)-\beta_{\text {Klett }}(z)}{\beta_{\text {Raman }}(z)+\beta_{\text {Klett }}(z)} .
$$

The elastic backscatter signals are corrected with $\Delta O_{i}(z)$ as follows:

$$
P_{0, i+1}(z)=P_{0, i}(z)\left[1+\Delta O_{i}(z)\right] .
$$

These steps are iteratively repeated in order to completely remove the overlap effect. From the comparison of the measured signal profile with the corrected signal profile, the overlap profile is derived. Finally, the overlap correction is applied to the lidar signals as follows:

$$
P_{\text {corrected }}(z, \lambda)=\frac{P_{\text {measured }}(z, \lambda)}{O(z, \lambda)},
$$

where $P_{\text {measured }}$ is the power received, $O(z, \lambda)$ is the overlap function and $P_{\text {corrected }}$ is the lidar power after the overlap correction. In order to 
obtain a more trustable overlap function, experimental points were fitted to function commonly used by the lidar community (logistic function):

$$
y=A_{2}+\frac{A_{1}-A_{2}}{1+\left(x / x_{0}\right)^{p}},
$$

where $A_{1}, A_{2}, x_{0}$ and $p$ are fitting parameters.

\section{Results}

\subsection{Overlap function retrieved under conditions of medium-low aerosol load and its reproducibility}

Lidar measurements (2 hours) performed during the night of 20.06.2010 was used to retrieve 4 different overlap functions. From the time series of lidar range corrected signal at 532 $\mathrm{nm}$ (Fig. 1) it can be inferred that there is very low presence of aerosols in the atmosphere above $2.5 \mathrm{~km}$ asl, therefore providing appropriate conditions for the evaluation of the overlap function. Clean conditions are necessary
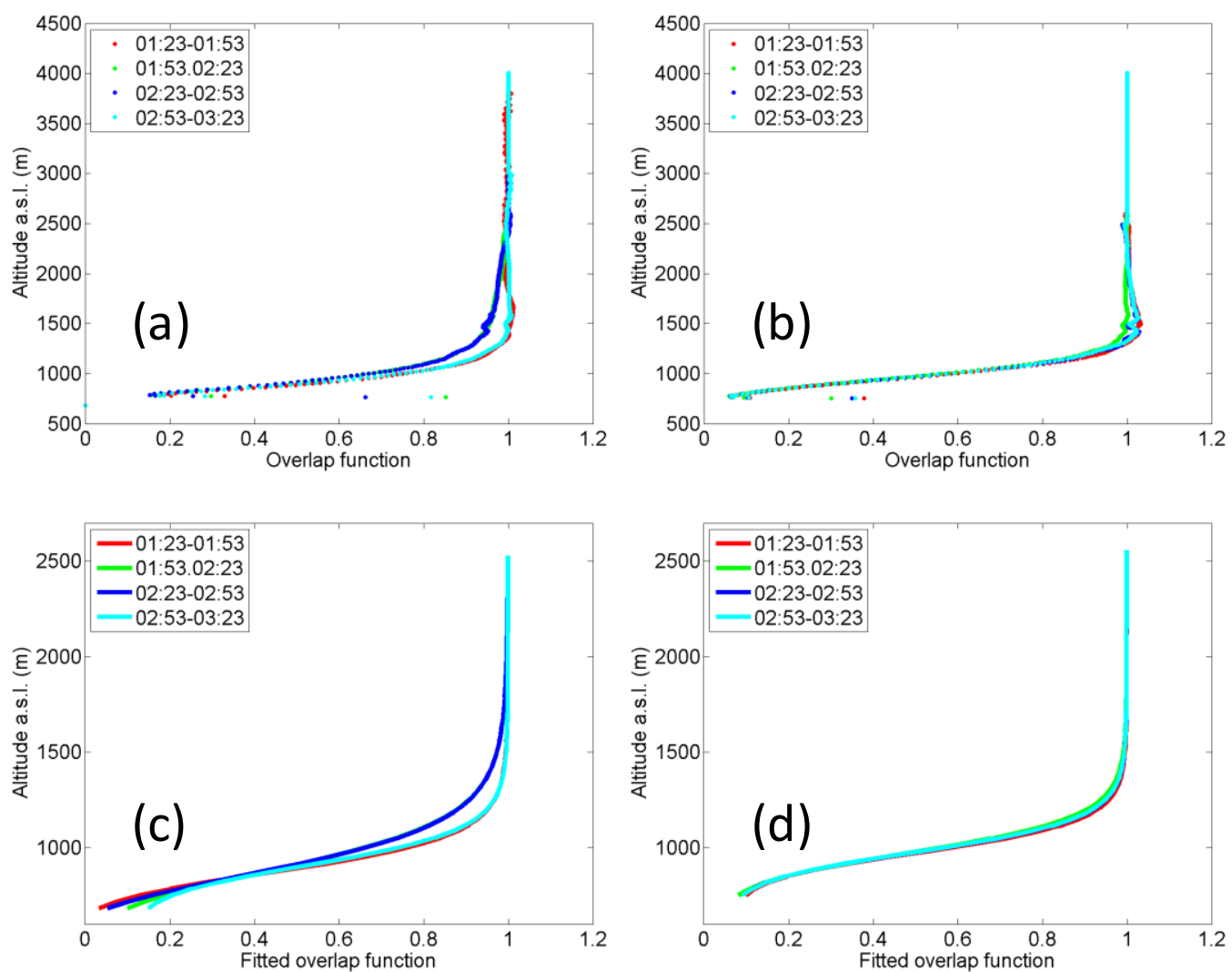

Fig. 2. (a) Overlap function for $355 \mathrm{~nm}$, (b) overlap function for $532 \mathrm{~nm}$, (c) fitted overlap function for $355 \mathrm{~nm}$, (d) fitted overlap function for $532 \mathrm{~nm}$. in order to minimize the effect of the lidar ratio on the retrievals.

The retrieved overlap functions are represented in Figs. 2a and $2 \mathrm{~b}$ for $355 \mathrm{~nm}$ and $532 \mathrm{~nm}$, respectively. From both plots, it is clear that the overlap function differs from value 1 in the lowermost part indicating an incomplete overlap from surface up to around $2000 \mathrm{~m}$ asl. As it can be seen overlap functions are very similar from the lowermost part of the profile up

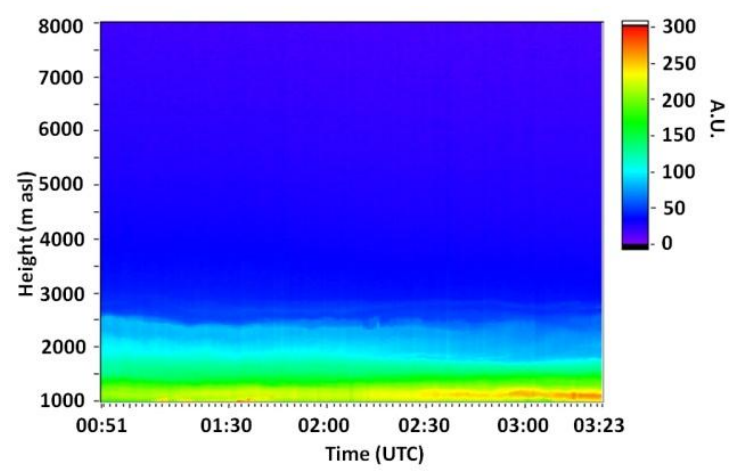

Fig. 1. Times series of range corrected signal at $532 \mathrm{~nm}$ (arbitrary units) for 20.06.2010. 
Table I

RMSE between the experimental data points and the fitted overlap function.

\begin{tabular}{ccc}
\hline Time UTC & RMSE at 355 nm & RMSE at 532 nm \\
\hline $01: 23-01: 53$ & 0.011 & 0.018 \\
$01: 53-02: 23$ & 0.035 & 0.012 \\
$02: 23-02: 53$ & 0.027 & 0.016 \\
$02: 53-03: 23$ & 0.031 & 0.016 \\
\hline
\end{tabular}

to $1250 \mathrm{~m}$ asl. Discrepancies found above 1250 $\mathrm{m}$ asl can due to changes in the assumed heightindependent lidar ratio value. In order to better characterize the overlap functions and to reduce the noise on these functions, the experimental data points were fitted to a logistic function. Fitted functions are represented in Figs. 2c and $2 \mathrm{~d}$. The assessment of these fits was performed through root mean square errors (RMSE) between originally retrieved and fitted functions (Table I). RMSE was in all the cases lower than 0.035 evidencing a considerably good fit.

In order to assess the reproducibility of the overlap function, the differences between the 4 fitted overlap functions have been computed using three different methods: RMSE, GFC (good fit coefficient) and oneway ANOVA test. For RMSE, two identical functions are identified with a value of 0 ; for GFC, two identical functions give a value of 1 and two completely different functions give value of 0 . These two methods compare just two functions to each other thus the values obtained are represented in Table II. Upper right part of the table represents RMSE and lower left part (including the diagonal) represents GFC. Maximum RMSE value for 355 $\mathrm{nm}$ was 0.045 and 0.015 for $532 \mathrm{~nm}$, whereas the minimum GFC values were 0.9991 and 0.9999 for 355 and $532 \mathrm{~nm}$, respectively. The obtained values show a better agreement between the 532-nm overlap functions, but even 355-nm overlap functions presented high degree of reproducibility. The better agreement for the overlap functions at $532 \mathrm{~nm}$ than for $355 \mathrm{~nm}$ could be due to the fact that the lidar ratio influences strongly to lower wavelengths. Oneway ANOVA test performs a comparison of the means of all functions. Values lower than 0.01 mean that at least one sample mean is significantly different than the other functions. For $355 \mathrm{~nm}$ we obtain a value of 0.9738 and for $532 \mathrm{~nm}$ a value of 0.9999 .
Table II

RMSE and GFC for overlap functions for 20.6.2010 for 355 $\mathrm{nm}$ (top) and $532 \mathrm{~nm}$ (bottom). Upper right diagonal of the matrix are values for RMSE, lower left diagonal of the matrix (including the diagonal) are values for GFC.

\begin{tabular}{|c|c|c|c|c|}
\hline \multicolumn{5}{|c|}{$355 \mathbf{~ n m}$} \\
\hline Period & 1 & 2 & 3 & 4 \\
\hline 1 & 1.0000 & 0.0446 & 0.0409 & 0.0249 \\
\hline 2 & 0.9991 & 1.0000 & 0.0100 & 0.0379 \\
\hline 3 & 0.9993 & 0.9999 & 1.0000 & 0.0401 \\
\hline 4 & 0.9996 & 0.9994 & 0.9993 & 1.0000 \\
\hline
\end{tabular}

\begin{tabular}{|c|c|c|c|c|}
\hline \multicolumn{5}{|c|}{$532 \mathbf{~ n m}$} \\
\hline Period & 1 & 2 & 3 & 4 \\
\hline 1 & 1.0000 & 0.0126 & 0.0058 & 0.0070 \\
\hline 2 & 0.9999 & 1.0000 & 0.0069 & 0.0058 \\
\hline 3 & 1.0000 & 1.0000 & 1.0000 & 0.0012 \\
\hline 4 & 1.0000 & 1.0000 & 1.0000 & 1.0000 \\
\hline
\end{tabular}

Taking into account the results for these three methods, the differences between the 4 overlap functions are negligible and an average overlap function was computed for 20.06.2010. Figure 3 shows average functions for both wavelengths with the corresponding standard deviation as the estimates of the variability of the overlap function.
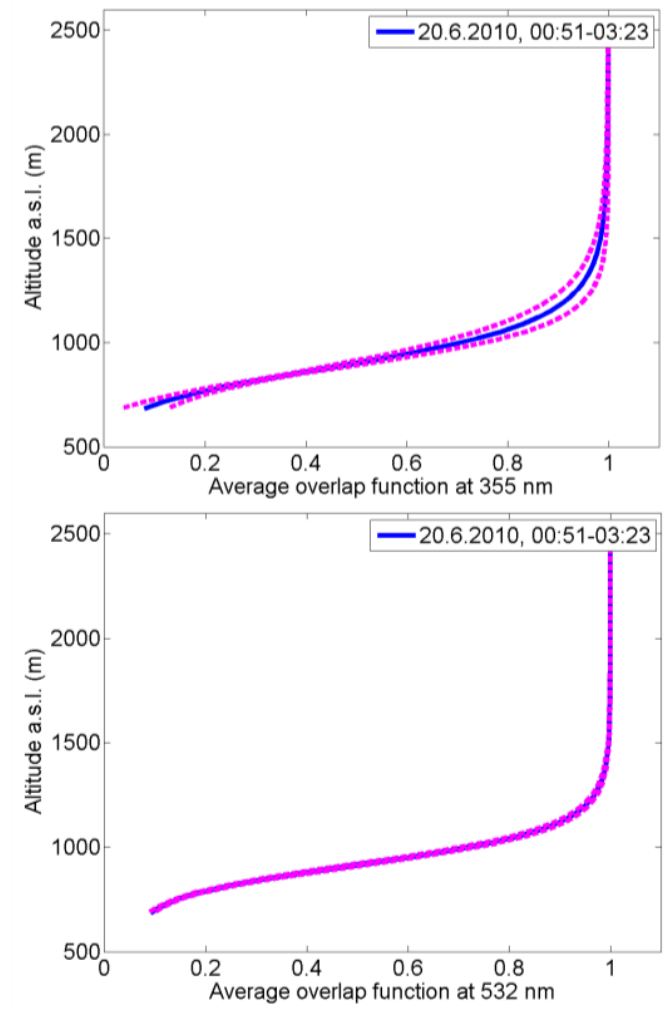

Fig. 3. Mean overlap function (blue) and its standard deviation (pink) for 20.6.2010 at $355 \mathrm{~nm}$ (top) and $532 \mathrm{~nm}$ (bottom). 


\subsection{Overlap function retrieved under different scenarios: a sensibility study}

In this section, the overlap functions were retrieved under different scenarios in order to investigative the influence of (i) the aerosol load present at the atmospheric column over the Raman lidar system and (ii) the number of iterations used to iteratively retrieve the overlap functions.

The effect of aerosol load is investigated through the comparison of the overlap functions retrieved under atmospheric conditions of high (07.07.2011) or low (20.06.2010) aerosol load. The time series of the lidar range corrected signal for the measurement performed on 07.07.2011 is shown in Fig. 4. A complex aerosol layering is detected during this lidar measurement with several aerosol layers from surface up to $2.5 \mathrm{~km}$ asl and a very thick $2-\mathrm{km}$ free tropospheric layer extending above $4.0 \mathrm{~km}$ asl.

Figure 5 depicts overlap functions retrieved under conditions of high and low aerosol load conditions. Two effects can be clearly identified. On one hand, the high aerosol load influences the overlap functions at both wavelengths reaching unity at higher altitude than under conditions of low aerosol load due to the impact of selection of a constant aerosol lidar ration for the Klett method. Thus, as Fig. 5 shows the 355-nm full overlap height increases from $1.5 \mathrm{~km}$ asl under low aerosol load to $3.0 \mathrm{~km}$ asl under high aerosol load, and the 532-nm full overlap height increases from $1.4 \mathrm{~km}$ asl under low aerosol load to $2.0 \mathrm{~km}$ asl under high aerosol load. On the other hand, the aerosol layering impacts on the

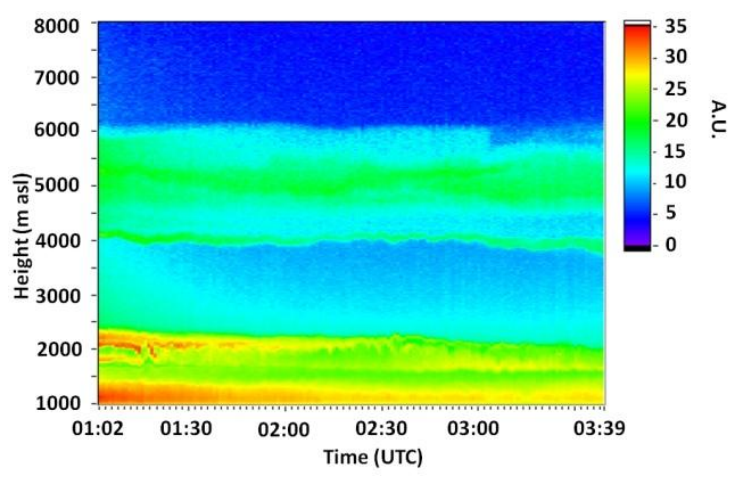

Fig. 4. Times series of range corrected signal at $532 \mathrm{~nm}$ (arbitrary units) for a night with high aerosol load. retrieved overlap functions altering the monotonic increase with altitude obtained under low aerosol load and, therefore, exhibiting some peaks at altitudes where strong aerosol layering is detected (around $1.5 \mathrm{~km}$ asl). As it is known, lidar signals at longer wavelengths allow to detect aerosol layering in a more contrasted way. This is the reason why the 532-nm overlap function retrieved under high aerosol load bears off the ideality more than the $355-\mathrm{nm}$ overlap function. These results indicate that to obtain trustworthy overlap functions is hugely recommendable to check the atmospheric conditions during measurements, in order to exclude measurements with high aerosol load.

Figure 6 illustrates the overlap functions at several stages of the iterative process described in section 2.2. The use of a low number of iterations generally implies that the overlap function does not properly converge to a realistic value, shown anomalous behavior with some unrealistic values larger than unity at
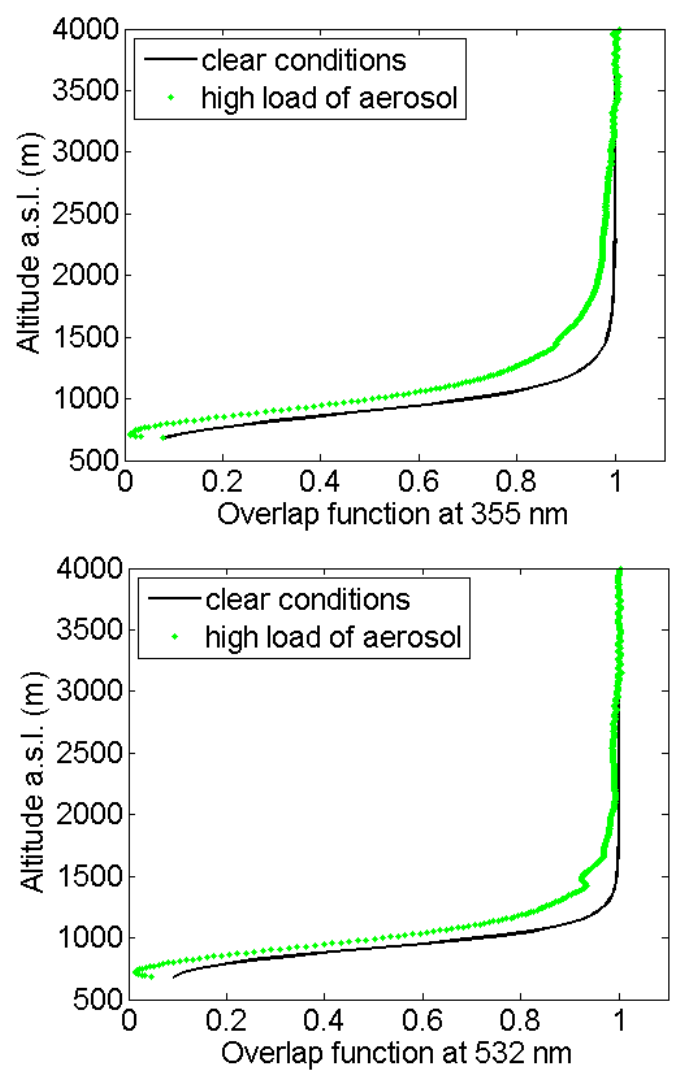

Fig. 5. Comparison of overlap functions under conditions of high aerosol load (07.07.2011) and low aerosol load (mean overlap functions on 20.06.2010) for 355 (top) and $532 \mathrm{~nm}$ (bottom). 


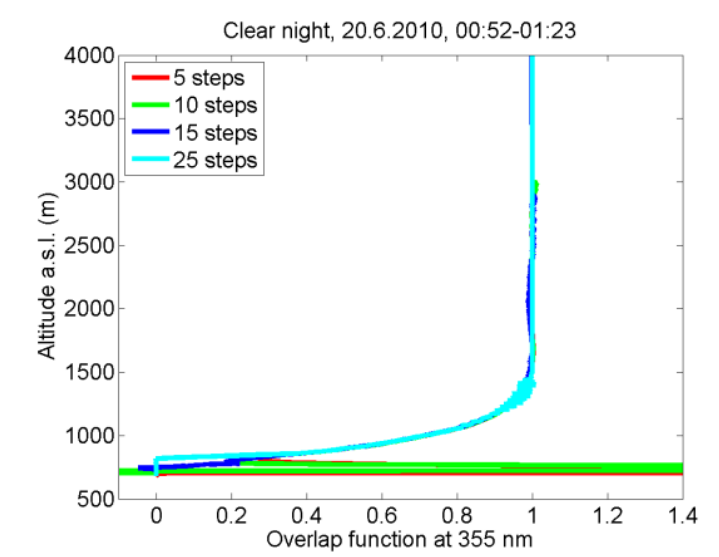

Fig. 6. 355-nm overlap function retrieved for differentiteration steps.

certain data points in the lowermost segments of the lidar overlap function. The optimum values of iterations used to be reached around 15 iterations for $355 \mathrm{~nm}$ and 20 iterations for 532 $\mathrm{nm}$. Moreover, our analyses have shown that the number of iterations needed to properly converge to a trustworthy overlap function can differ depending on the atmospheric conditions. Thus, more iterations are required to obtain a reliable overlap function under scenarios with high aerosol loads due to the complex vertical distribution of aerosol particles might imply a complex vertical distribution of particle lidar ratio. A large number of iterations could affect by deforming the retrieved overlap functions.

\section{Conclusions}

The lidar overlap function for the Raman lidar system at the EARLINET Granada station has been retrieved at two wavelengths analyzing the aerosol backscatter profiles retrieved from the Raman and Klett-Fernald methods. The reproducibility of the overlap function has been investigated under different atmospheric conditions. Thus, our retrievals of overlap functions were found to be quite stable during situations of low aerosol load, as occurred on 20.06.2010 where values of $\mathrm{RMSE}<0.045$ and
GFC $>0.9991$ were found for the 355-nm overlap functions. Our results for the 532-nm overlap functions showed even better reproducibility. Under conditions of high aerosol load with complex layering, overlap functions are affected by increasing the altitude where the full overlap is reached, especially at $355 \mathrm{~nm}$. In addition, the complex aerosol layering (more evidenced on the 532-nm profiles) causes modifications on the retrieved overlap functions introducing some peaks on the expected overlap functions at altitudes where strong aerosol layering is detected. Finally, special attention has been paid to the iteration process itself in order to assess the effect of the iteration number on the retrieved overlap functions. As was expected, when a low number of iterations is used the overlap function does not properly converge to a realistic value. The optimum values of iterations used to be reached around 15 iterations for 355 $\mathrm{nm}$ and 20 iterations for $532 \mathrm{~nm}$. However, this number might change depending on the atmospheric conditions, and typically more iterations are required under scenarios with high aerosol loads due to the complex aerosol layering.

\section{Acknowledgements}

This work was supported by the Spanish Ministry of Science and Technology through project CGL2008-01330-E/CLI (Spanish and Portuguese Lidar Network); by the Spanish Ministry of Economy and Competitiveness through projects CGL2010-18782, CSD200700067, CGL2011-13580-E/CLI and CGL201116124-E; by the Andalusian Regional Government through projects P10-RNM-6299 and P12-RNM-2409; by the University of Granada through the contract "Plan Propio. Programa 9. Convocatoria 2013"; and by EU through ACTRIS project (EU INFRA-2010-1.1.16262254). 